\title{
Seasonal dynamics of nutrients and organic matter in urban stream
}

\author{
Oxana Erina*, Dmitriy Sokolov, Maria Tereshina, Jessica Vasil'chuk, and Nikolay \\ Kasimov \\ Lomonosov Moscow State University, Faculty of Geography, GSP-1, 1 Leninskiye Gory, 119991, \\ Moscow, Russia
}

\begin{abstract}
The study presents the results of water quality evaluation in the Setun River watershed, located entirely within the limits of the Moscow City. Multiple point and non-point sources of pollution cause the nutrient and organic matter content of the river and its tributaries to significantly differ from the natural background. Maximum nitrogen and phosphorus concentrations were observed at the upper reaches of the river during the summer low flow due to the landfill impact. Because of the extreme nutrient pollution at the river's upper course, subsequent water inflow, even from significantly polluted tributaries, has a diluting effect, and the nutrient concentration decreases downstream. The effect of urbanization on the organic matter content is reflected in elevated COD and BOD values that exceed the national environmental guidelines. Seasonal dynamics of organic matter content includes increased organic matter during snowmelt and its relatively low content during summer.
\end{abstract}

\section{Introduction}

The urban environment contains many unfavorable factors for the water quality [1]. Urban streams typically have altered runoff patterns and often receive larger volumes of municipal and industrial wastewater [2]. Multiple non-point pollution sources, such as roads and landfills, also tend to concentrate within urban watersheds [3]. Furthermore, consistent urban impact on soil and groundwater pollution can result in a legacy effect, therefore perpetuating surface water pollution for decades after the initial pollution source is eliminated [4].

Seasonal dynamics of the urban water chemistry is also different from areas with lower urbanization levels. For instance, in winter and spring, urban streams experience salinization due to the use of deicing agents that cause unnaturally high chloride levels [5]. During the periods of low water flow, reduced self-purification capacity of urban rivers causes an increase in nutrient and organic matter content, whereas in natural streams summer concentrations of these substances are usually the lowest in the year [6].

The degradation of aquatic ecosystems as a result of urban impact has become known as the «urban stream syndrome» [7]. Although the global experience includes many successful

\footnotetext{
* Corresponding author: oxana.erina@geogr.msu.ru
} 
cases of urban river restoration, it is necessary to understand the key challenges for each subject to clearly formulate an effective watershed management strategy. In Russia, the main problem in watershed management is insufficient coverage of the national environmental monitoring data and its inaccessibility for public use and academic research. Because of that, it is often necessary to conduct additional detailed studies as the first step in developing an ecological restoration strategy.

The aim of this study is to determine the intensity of the urban stream syndrome for a small river in the Moscow City affected by multiple stressors. The smallest streams are the most vulnerable to the human impact due to their inherently low self-purification capacity. Rivers of a smaller scale experiencing a multi-layered environmental stress are predominant in the Moscow City [8], which allows extending the outcome of this study to represent the issues of the Moscow City's overall river water pollution.

\section{Materials and methods}

The subject of this study is the Setun River basin (Fig. 1), located in the western part of the Moscow City. The Setun is a right tributary of the Moskva River, it is $38 \mathrm{~km}$ long and has a drainage area of $190 \mathrm{~km}^{2}$. Despite its small size, many sources of anthropogenic pollution are located within the Setun watershed; many of them affect the river's water quality. The Setun's source is situated close to a municipal solid waste landfill in the Salarievo district [9-10]; the landfill is currently closed and recultivated, but continues to release contaminants into the surface and groundwater. Multiple roads and highways cross the Setun River, including the Moscow Automobile Ring Road. Although some part of the Setun's watershed lies within a nature reserve, the river receives municipal runoff from entire Moscow City districts (e.g. Solntsevo), and most of its tributaries are severely industrially polluted. For some of the streams, wastewater forms a larger portion of their total runoff than natural water inflow.

In 2019, we conducted an extensive study to see how the water quality changes along the course of the Setun River. The observation points were set downstream from expected pollution sources - large roads, major wastewater outflows etc. The sampling was carried out during the spring flood and in the low flow period - in April and August 2019 - to explore the seasonal dynamics of the water quality and identify the effect of point source pollution.

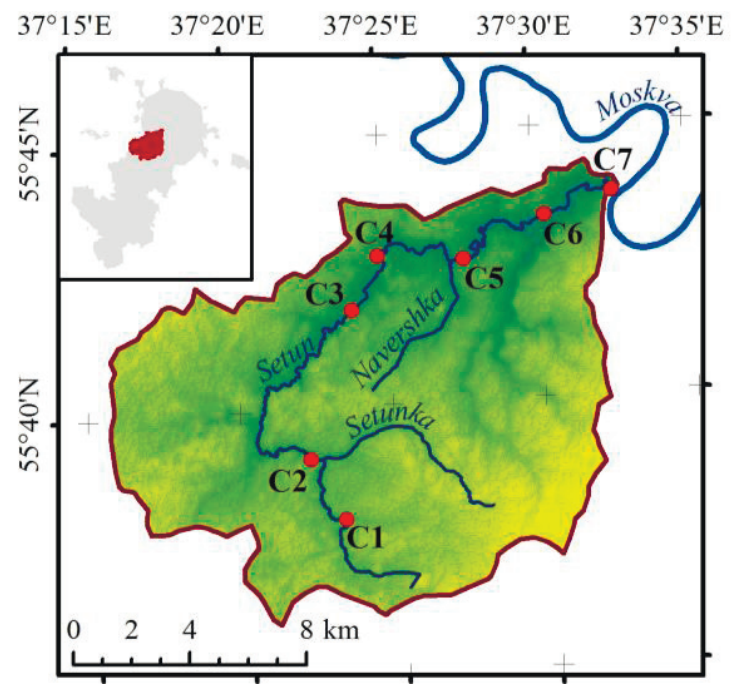

Fig. 1. The Setun River basin and water sampling points in 2019. 
Ion chromatography was used to determine the content dissolved ammonia, nitrites and nitrates. Total and dissolved phosphorus (organic and inorganic) and total nitrogen content was determined using photometric methods [11-12]. Organic matter content was estimated by $\mathrm{COD}$ and $\mathrm{BOD}$ - two indirect measurements that are widely used to assess organic water pollution.

\section{Results and discussion}

\subsection{Nutrients}

Spatial and temporal patterns of nutrient content in the Setun River were characteristic of a stream with high level of anthropogenic pollution.

The total nitrogen content steadily decreased along the river's course in both seasons. During the snowmelt, up to $46 \%$ of $\mathrm{TN}$ was transported as particulate nitrogen, whereas in the summer its percentage did not exceed $10-15 \%$ (Fig. 2). At the same time, maximum summer concentration of total nitrogen was significantly higher than the maximum spring concentration, which indicates a presence of an anthropogenic nitrogen pollution source. The Salarievo landfill at the upper part of the watershed can be considered the greatest source of nitrogen supply into the Setun River. The water inflow between the first and second points dilutes the wastewater input from the landfill, decreasing the TN content by half. Further dilution and self-purification cause the nitrogen concentration at the river's mouth to drop to $2.8 \mathrm{mg} / \mathrm{L}$ in April and to $2.1 \mathrm{mg} / \mathrm{L}$ in August. The ratio between particulate and dissolved nitrogen at the last point is nearly unchanged between the seasons with particulate nitrogen percentage of $16 \%$.
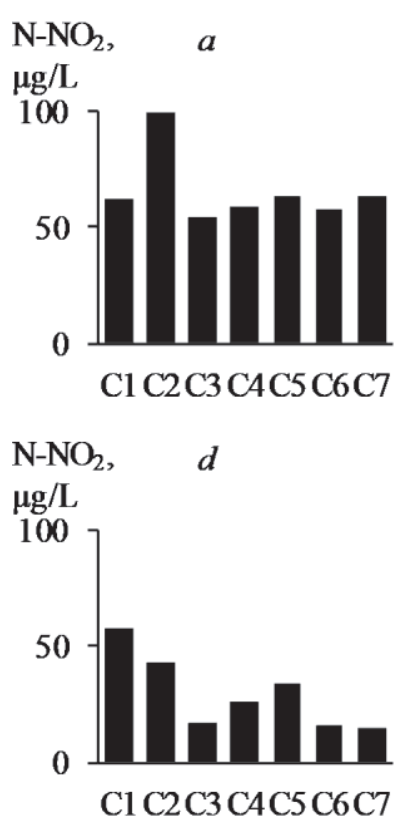
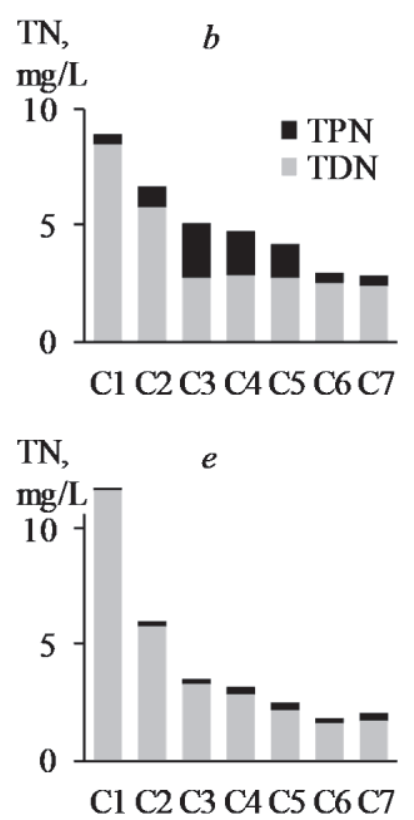
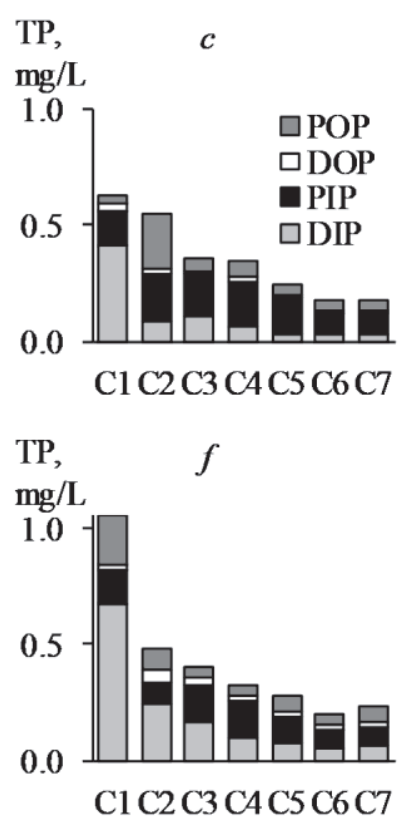

Fig. 2. Nitrites $(a, d)$, dissolved (DTN) and particulate (PTN) total nitrogen $(b, e)$, and phosphorus (DIP - dissolved inorganic phosphorus, PIP - particulate inorganic phosphorus, DOP - dissolved organic phosphorus, POP - particulate organic phosphorus) $(c, f)$ concentrations in the Setun River in April $(a-c)$ and August $(d-f) 2019$. 
The nitrite concentration shows clear seasonal variation with increased spring and decreased summer values. Elevated nitrite content in the spring time is caused by organic pollutant inflow via snowmelt. It is confirmed by elevated nitrite nitrogen concentration observed in April at the $\mathrm{C} 2$ station, where the wastewater from the urban snow disposal site reaches the river. In general, the nitrite content in the Setun River is much higher than typical for rivers unaffected by human activity.

The phosphorus content is also significantly affected by the Salarievo landfill. Maximum total phosphorus concentration was observed at the river's source in summer and exceeded $1 \mathrm{mg} / \mathrm{l}$, while the TP content during the spring flood was $40 \%$ lower. This seasonal pattern is not normally seen in natural bodies of water and is indicative of severe pollution. Lowered spring TP compared to the summer values is explained by relatively small nutrient concentration in the snowmelt, which dilutes the landfill wastewater to some extent. The ratio between different forms of phosphorus indicates groundwater pollution at the upper reaches of the river. Major part of the TP increase is contributed by dissolved inorganic phosphorus; the organic phosphorus percentage is nearly constant between the stations and remains around $10 \%$ in both spring and summer. The $\mathrm{C} 2$ station exhibits the strongest seasonal variation, showing significant rise in organic phosphorus content in the spring, likely caused by runoff from the snow disposal plant.

It should be noted that in most of the samples collected on the Setun River in both April and August, nitrite and mineral phosphorus concentrations exceeded the national environmental guidelines for water objects by up to 5 times.

\subsection{Organic matter}

Seasonal and spatial dynamics of the organic matter content in the Setun River exhibit a greater influence of natural aspects than the urban environment impact.

The 5-day biochemical oxygen demand $\left(\mathrm{BOD}_{5}\right)$ provides an assessment of a labile organic matter $(\mathrm{OM})$ content. Maximum $\mathrm{BOD}_{5}$ values in both April $\left(8.6 \mathrm{mgO}_{2} / \mathrm{L}\right)$ and August $\left(4.9 \mathrm{mgO}_{2} / \mathrm{L}\right)$ were noted at the $\mathrm{C} 2$ station below the wastewater outflow. The spatial variation of $\mathrm{BOD}_{5}$ was greater in April than in August, likely due to a high heterogeneity of the watershed's snow cover. The total labile organic matter content in the river was increased during snowmelt, but a larger portion of runoff was generated at the upper reaches of the watershed with generally undisturbed landscapes than at its lower reaches. In the summer, the spatial variation and maximum values of $\mathrm{BOD}_{5}$ were much lower, but still exceeded the environmental guideline $\left(2 \mathrm{mgO}_{2} / \mathrm{l}\right)$ at each observation point.

The chemical oxygen demand (COD), which serves as a measure of the total organic matter content, was about $30-40 \%$ higher in spring than it was in summer. Similar to BOD, the $\mathrm{COD}$ value peaked at the $\mathrm{C} 2$ station because of the wastewater intake; another local maximum was observed at the C5 station, located downstream of the Navershka River inflow. This extreme value reached $128 \mathrm{mgO} / \mathrm{L}$ and may have likely been caused by an illegal sewage discharge into the Navershka River, which crosses an industrial zone. In the summer, the COD values in both the Navershka and the Setun River at the C5 station were much lower - 37 and $31 \mathrm{mgO} / \mathrm{L}$, respectively - indicating that this was a singular wastewater disposal event. The $\mathrm{COD} / \mathrm{BOD}_{5}$ ratio was also the greatest at the $\mathrm{C} 5$ station in April, indicating an intake of non-biodegradable organic matter, which suggests industrial organic waste rather than municipal sewage.

In both spring and summer, dissolved organic matter was predominant in the total OM of the Setun River, as the particulate matter input in the COD value did not exceed $10 \%$. It can be concluded that the Setun River currently has very high organic matter content with COD value consistently exceeding the national water quality guideline of $15 \mathrm{mgO} / \mathrm{L}$. 

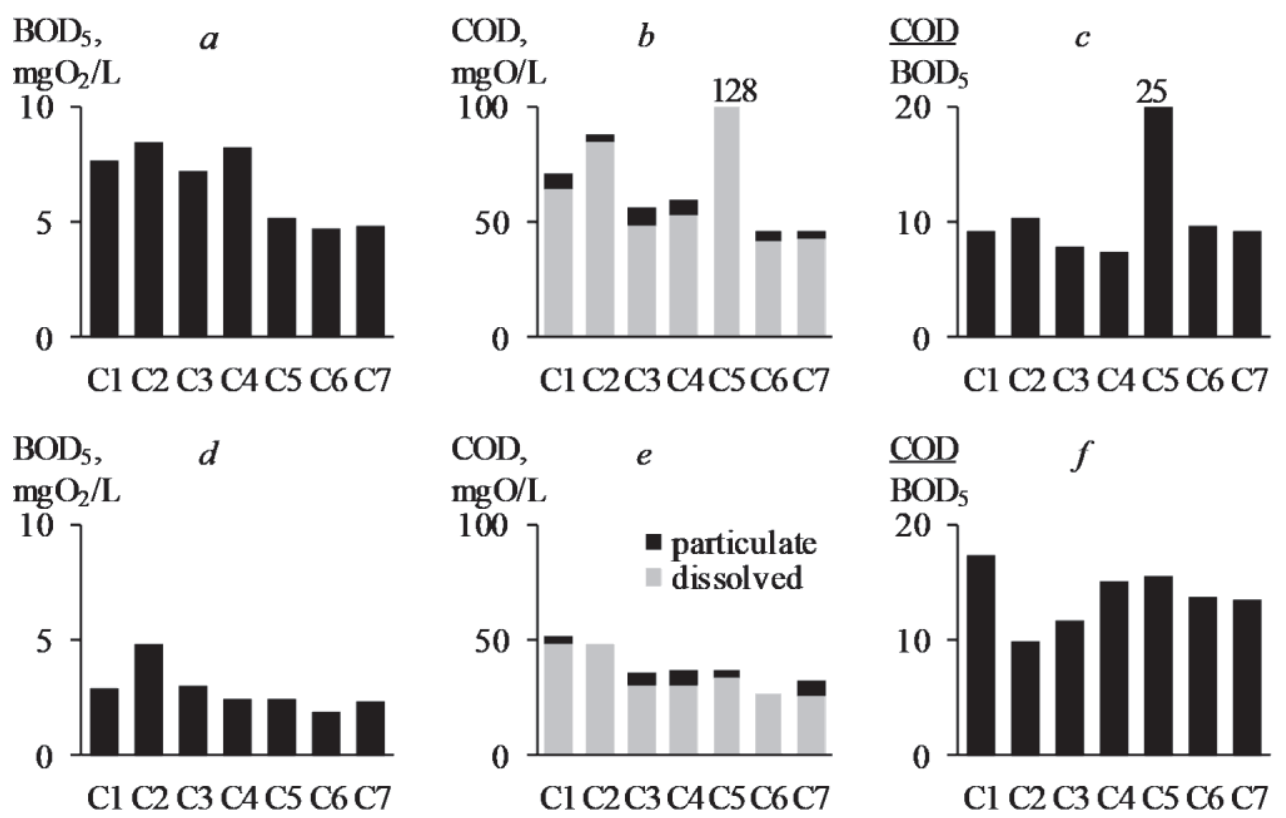

Fig. 3. $\mathrm{BOD}(a, d)$, $\mathrm{COD}$ (dissolved (DOM) and particulate (POM) $(b, e)$, and the $\mathrm{COD} / \mathrm{BOD}_{5}$ ratio $(c, f)$ in the Setun River in April $(a-c)$ and August $(d-f) 2019$.

\section{Conclusions}

Observed seasonal dynamics of nutrient and organic matter content in the Setun River is influenced by both natural aspects and anthropogenic impact. Natural features include increasing organic matter content during snowmelt compared to summer values, as well as normal ratios between particulate and dissolved forms of nitrogen, phosphorus and organic matter.

One of the clear examples of anthropogenic impact on the Setun's water quality is the unnaturally high content of total nitrogen and phosphorus during summer low flow that exceed the spring flood levels by almost twice.

The negative environmental impact is further demonstrated by elevated COD and BOD, whose values continuously exceed the national guidelines. The wastewater treatment facilities in the Setun watershed clearly do not provide sufficient OM removal, as the OM content was regularly elevated downstream from their outlets.

It can be concluded that non-point pollution has a greater negative effect on the Setun water quality than direct wastewater discharge. Wastewater inflow may even provide certain dilution potential to decrease the contamination from the Salarievo municipal landfill, which can be singled out as the greatest source of nutrient and organic pollution on the Setun watershed.

This study was supported by the Russian Science Foundation (project no. 19-77-30004). 


\section{References}

1. R. Xiao, G. Wang, Q. Zhang, Z. Zhang, Sci. rep., 6(1), 1 (2016)

2. R.M. Mulliss, D.M. Revitt, R.B. Shutes, Sci. Total Environ., 189, 385 (1996)

3. M.C. Maniquiz, S. Lee, L.H. Kim, J. Environ. Sci., 22(6), 946 (2010)

4. M.A. Kaya, G. Özürlan, E. Şengül, Environ. Monit. Assess., 135(1-3), 441 (2007)

5. S.S. Kaushal, G.E. Likens, M.L. Pace, S. Haq, K.L. Wood, J.G. Galella, C. Morel, T.R. Doody, B. Wessel, P. Kortelainen, A. Räike, V. Skinner, R. Utz, N. Jaworski, Phil. Trans. R. Soc. B, 374(1764), 20180017 (2019)

6. E.S. Bernhardt, L.E. Band, C.J. Walsh, P.E. Berke, Annals of the New York Academy of Sciences, 1134(1), 61 (2008)

7. C. J., Walsh, A. H., Roy, J. W., Feminella, P. D., Cottingham, P. M., Groffman, R. P. \& Morgan, J. N. Am. Benthol. Soc., 24(3), 706 (2005)

8. D. Kramer, I. Tikhonova, WIT Trans. Ecol. Envir., 196, 447 (2015)

9. E. Gogina, A. Pelipenko, MATEC Web Conf., 73, 03007 (2016)

10. L.V. Mosina, Y.A. Zhandarova, V.V. Bekk, SUITMA 9. Urbanization: a challenge and an opportunity for soil functions and ecosystem services, 214 (2017)

11. J. Murphy, J.P. Riley, Anal. Chim. Acta, 27, 31-36 (1962)

12. L.M.L. Nollet, L.S.P. De Gelder, Handbook of Water Analysis (CRC Press, 2013) 